\title{
Split sex ratios and genetic relatedness in a primitively eusocial sweat bee
}

\author{
Tanya M Pennell ${ }^{1} \cdot$ Jeremy Field ${ }^{1}$
}

Received: 21 September 2020 / Revised: 24 November 2020 / Accepted: 30 November 2020 / Published online: 11 December 2020

(C) The Author(s) 2020

\begin{abstract}
In eusocial Hymenoptera, queens and their helper offspring should favour different sex investment ratios. Queens should prefer a 1:1 investment ratio, as they are equally related to offspring of both sexes $(r=0.5)$. In contrast, helpers should favour an investment ratio of 3:1 towards the production of female brood. This conflict arises because helpers are more closely related to full sisters $(r=0.75)$ than brothers $(r=0.25)$. However, helpers should invest relatively more in male brood if relatedness asymmetry within their colony is reduced. This can occur due to queen replacement after colony orphaning, multiple paternity and the presence of unrelated alien helpers. We analysed an unprecedentedly large number of colonies $(n=109)$ from a UK population of Lasioglossum malachurum, an obligate eusocial sweat bee, to tease apart the effects of these factors on colony-level investment ratios. We found that multiple paternity, unrelated alien helpers and colony orphaning were all common. Queen-right colonies invested relatively more in females than did orphaned colonies, producing a split sex ratio. However, investment ratios did not change due to multiple paternity or the presence of alien helpers, reducing inclusive fitness pay-offs for helpers. Queen control may also have been important: helpers rarely laid male eggs, and investment in female brood was lower when queens were large relative to their helpers. Genetic relatedness between helpers and the brood that they rear was 0.43 in one year and 0.37 in another year, suggesting that ecological benefits, as well as relatedness benefits, are necessary for the maintenance of helping behaviour.
\end{abstract}

\section{Significance statement}

How helping behaviour is maintained in eusocial species is a key topic in evolutionary biology. Colony-level sex investment ratio changes in response to relatedness asymmetries can dramatically influence inclusive fitness benefits for helpers in eusocial Hymenoptera. The extent to which helpers in primitively eusocial colonies can respond adaptively to different sources of variation in relatedness asymmetry is unclear. Using data from 109 colonies of the sweat bee Lasioglossum malachurum, we found that queen loss, but not multiple paternity or the presence of alien helpers, was correlated with colony sex investment ratios. Moreover, we quantified average helper-brood genetic relatedness to test whether it is higher than that predicted under solitary reproduction $(r=0.5)$. Values equal to and below $r=0.5$ suggest that relatedness benefits alone cannot explain the maintenance of helping behaviour. Ecological benefits of group living and/or coercion must also contribute.

Keywords Investment ratio $\cdot$ Relatedness $\cdot$ Social evolution $\cdot$ Sweat bee

Communicated by J. Heinze

Tanya M Pennell

t.pennell@exeter.ac.uk

1 College of Life and Environmental Sciences, University of Exeter, Penryn, UK

\section{Introduction}

Eusociality has evolved multiple times in insects (Wilson, 1971), especially in the order Hymenoptera (ants, bees and wasps). Eusocial groups are characterised by a reproductive division of labour, whereby queens produce most of the brood while some of their offspring forgo reproduction in order to help raise siblings. Nevertheless, there is potential conflict between queens and helpers over issues such as male production, queen tenure and the trait we will focus on here, the sex 
investment ratio (Trivers and Hare, 1976; Bourke, 1994; Ratnieks et al., 2006; Ratnieks and Reeve, 1992). The sex investment ratio preferred by helpers depends on various factors. In haplodiploids, helpers are more closely related to their full sisters $(r=0.75)$ than their brothers $(r=0.25)$, so that under queen monogamy and helper sterility, they should favour an investment ratio of 3:1 towards the production of female brood (Trivers and Hare, 1976). However, between-colony differences in relatedness asymmetries can alter the optimum investment ratio for helpers (Boomsma, 1991; Pamilo, 1991). Relatedness asymmetries are reduced by the death of queen (i.e. where a helper replaces the queen as the primary reproductive: Chapuisat and Keller, 1999; Meunier et al., 2008; West, 2009), by multiple paternity (Ratnieks and Boomsma, 1996) and by the presence of unrelated 'alien' helpers (Pfeiffer and Crailsheim, 1998; Soro et al., 2009). Helpers should then invest relatively more in the production of male brood, or be more likely to lay their own male eggs, in order to maximise their inclusive fitness. In line with this, evidence from studies of bees, wasps and ants suggest that helpers can adjust the investment ratio to some degree, depending on their perception of genetic structure within the colony (Packer and Owen, 1994; Ross and Matthews, 1989a, 1989b; Sundström, 1994; Sundström et al., 1996), although other studies of bees and ants have found no evidence for helper adjustment of colony investment ratios (Paxton et al., 2002a; Fjerdingstad et al., 2002; Foitzik et al., 2010). It is possible that the extent of helper control depends on the source of variation in relatedness asymmetry and the cues used to assess it. For example, it is plausible that helpers might respond to the death of the queen (normally a noticeably larger individual), but are unable to recognise more subtle differences in relatedness asymmetry, such as when brood are sired by different fathers (Soro et al., 2011). A meta-analysis based on a small number of studies in social Hymenoptera found that the extent of sex allocation adjustment did not depend on the source of relatedness asymmetry variation (Meunier et al., 2008), but more research combining estimates of investment ratios and relatedness are needed. If helpers are unable to respond to all sources of variation in relatedness asymmetry, then this could severely limit their inclusive fitness benefits.

Helper inclusive fitness could also be limited if queens are able to gain control of the investment ratio. Queens are related to male and female offspring equally $(r=0.5)$ and therefore favour a 1:1 investment ratio. In haplodiploids, mothers can directly control the sex of individual offspring through whether they release sperm to produce a fertilised (female) egg or an unfertilised (male) egg. Queens could therefore manipulate helpers into rearing more males by altering the primary offspring sex ratio. Nonetheless, it is common to observe investment ratios that are biased towards females, which may indicate helper control (Bourke and Franks, 1995; Chapuisat and Keller, 1999;
Trivers and Hare, 1976), although more recent research suggests that shared control is more likely, with investment ratios intermediate between queen and helper optimal values (Mehdiabadi et al., 2003).

As well as potentially influencing investment ratios, genetic relatedness is a key factor in the maintenance of eusociality itself. In order for relatedness benefits alone to favour helping, we should expect to see high helper-brood relatedness across colonies $(r>0.5)$. However, data from primitively eusocial insects are limited and so far show mixed results, with some studies reporting high (Crozier et al., 1987; Kukuk, 1989; Ross and Matthews, 1989a, 1989b), and others lower estimates of nest mate relatedness (Packer and Owen, 1994; Brand and Chapuisat, 2016; Gadagkar, 2016; Sumner et al., 2007). If relatedness benefits are not sufficiently high, then additional ecological advantages of group living might also be required to explain the maintenance of helping behaviour. Such benefits include insurance-based advantages of helping (Bull and Schwarz, 2001; Field et al., 2000; Gadagkar et al., 1990; Queller, 1994) and increased probability of successful reproduction (Dunn and Richards, 2003; Hogendoorn and Zammit, 2001; Leadbeater et al., 2011; Yagi and Hasegawa, 2012). Helpers might be also be manipulated into helping at their natal nests (Richards et al., 1995; Lopez-Vaamonde et al., 2004; Leadbeater et al., 2011). For example, if queens manipulate the developmental trajectories of helper offspring through nutrition, so that helpers are small, then helpers might have reduced chance of success if they attempt to initiate their own nests (Alexander, 1974; Couchoux and Field, 2019).

Sweat bees (Hymenoptera: Halictidae) include species displaying diverse social behaviours, including strictly solitary, facultatively eusocial and obligately eusocial species (Schwarz et al., 2007). In social sweat bees, there is a low degree of caste dimorphism and all individuals, including helpers, retain the ability to reproduce (Wyman and Richards, 2003; Richards et al., 2005). The obligately eusocial Lasioglossum malachurum has been well studied and is consequently an ideal system for testing theories about the maintenance of eusociality. Queen replacement by helpers is welldocumented in sweat bees (Boomsma, 1991; Packer and Owen, 1994; Yanega, 1989), but has not been explicitly studied in L. malachurum, although helper ovary development and occasional helper reproduction have been found in queenright colonies (Wyman and Richards, 2003; Richards et al., 2005; Strohm and Bordon-Hauser, 2003). Multiple paternity (Cole, 1983; Ratnieks and Boomsma, 1996; Soro et al., 2009) and the presence of alien helpers (Paxton et al., 2002b; Richards et al., 2005; Soro et al., 2009) have also been documented in sweat bees, including L. malachurum. However, data on colony-level investment ratios combined with relatedness estimates within a population are limited in sweat bees (Packer and Owen, 1994), and do not exist for L. malachurum. It is thus unclear as to what extent helpers 
of most species are able to adjust investment ratios in response to colony genetic structures. We used microsatellite genotyping of adults and brood, combined with weight measurements of male and female pupae, to determine investment ratios across more than 100 colonies from a site in the UK. Using these data, we (1) compared colony-level investment ratios in queen-right versus orphaned colonies; (2) tested for correlates of variation in the investment ratio in queen-right colonies, including the proportion of alien helpers, the number of fathers and overall helper-female brood relatedness; (3) quantified the average relatedness of helpers to brood, both in queenright and orphaned colonies.

\section{Materials and methods}

\section{Study species and study site}

We studied L. malachurum at an aggregation in Knepp Rewilding Estate in Sussex, UK, over two successive years (2017 and 2018). This species forms annual colonies, consisting of underground nests in patches of bare soil. Our site was a track-way used by people and occasional vehicles, with a south-facing aspect, low-exposure and a mild climate. Within the ca. $20 \mathrm{~m} \times 5 \mathrm{~m}$ site, thousands of nests could be found, which is not unusual for L. malachurum (Knerer, 1992). The following summary of its life cycle is based on Packer and Knerer (1985). The season begins with a founding phase in early spring, where overwintered, mated females (potential queens) emerge to start nest building. Potential queens work alone to excavate a burrow and mass provision a cluster of $\sim 5$ sealed brood cells with pollen, each containing a single first brood (B1) offspring. In this study, all of the B1 offspring were female, although previous research at other sites has sometimes found a low percentage $(<3 \%)$ of males in the B1 brood of L. malachurum. B1 females emerge in early summer and remain in the colony as helpers, provisioning a B2 brood consisting of reproductives of both sexes. During this time, queens remain almost exclusively inside the nest and dominate reproduction. In late summer, B2 reproductives emerge from the nest and mate. Males are short-lived, whereas females overwinter after mating and re-start the nesting cycle the following spring.

In the winter prior to each field season (2017 and 2018), 14-L plastic buckets were embedded into the ground and filled with the excavated soil. To aid drainage, buckets had holes cut into the base, which were covered by fine mesh gauze. During the founding phase, we marked the position of nests within buckets with numbered nails either side of the nest entrances. Colonies that had successfully produced B1 helper offspring were monitored daily (2017: $n=35$; 2018: $n=74)$.

\section{Group size}

We determined group size for a subset of queen-right colonies ( $n=23$ for 2017 and $n=36$ for 2018). The group size for a given day for each nest was measured by video recording bee activity at the nest for a full day. Cameras (Sony HDRCX625) were placed on tripods $>1 \mathrm{~m}$ from the bucket and pointed towards the nest entrance. Recording took place during the active foraging period from 9 am until $6 \mathrm{pm}$. To minimise nest disturbance, all tripods and cameras were set up by $8 \mathrm{am}$, prior to helpers leaving the nest and orientating themselves. Equipment was taken down after 6 pm, by which time helpers would typically have returned to the nest. Videos were played back (QuickTime version 10.5) at a maximum of $10 \times$ speed. After recording the sequence of helper arrivals and departures, we estimated the size of the group as the maximum number of helpers that were away from the nest during the day. We determined the maximum group size from an average of $3.5 \pm 0.1$ days of filming per nest from 2017 and an average of $2 \pm 0$ days per nest from 2018. In 2018, although the number of filming days was reduced, nests were filmed on days when group sizes were expected to be at their peak, as predicted from the 2017 data. Each colony had a single helper removed as it departed from the nest to forage $\sim 1$ week after B1 offspring had emerged $(7.8 \pm 0.3$ days in $2017 ; 7.4 \pm$ 0.2 days in 2018), as part of another study. These 'removed helpers' were accounted for when calculating the maximum group size. For example, if the maximum number of helpers identified from the video playback was 3 , but we removed a helper prior to filming, then the maximum group size for that colony was recorded as 4 . In two cases, the maximum group size identified from videos was lower than the number of helpers found during nest excavation. However, in both cases, one helper was found with a high level of wing damage, which could have prevented her from leaving the nest to forage.

\section{B2 sex investment ratio}

We began to remove buckets from the ground after a mean of 18 days \pm 0.5 (2017) and 15 days \pm 0.4 (2018) of nest activity after B1 emergence. For $60 \%$ and $31 \%$ of nests, the B1 foraging phase had ceased prior to excavation in 2017 and 2018 respectively. Each bucket was removed early in the morning prior to helper activity, and nest entrances were blocked to ensure all of the adults remained in the nest. Buckets were then excavated on the day of removal. Coloured talcum powder was used to follow tunnels and locate the brood cells. All B2 brood and adults (B1 and queens) belonging to each nest were collected and preserved (B2 brood in tubes of $100 \%$ ethanol, stored at $4{ }^{\circ} \mathrm{C}$; adults in RNAlater, stored at $\left.80^{\circ} \mathrm{C}\right)$. B2 brood were found at egg, larval and pupal stages.

The sex of each B2 brood was determined by microsatellite genotyping (see section: 'Microsatellite genotyping and 
relatedness'). To determine the investment ratio (the relative investment in male and female brood) for each colony, we multiplied the number of male and female B2 by mean male and female weight, respectively. Mean male and female weight was calculated in 2017 by averaging weights across 61 male pupae $(0.021 \mathrm{~g} \pm 0.001)$ and 60 female pupae (0.036 g \pm 0.001$)$, respectively (wet weight; Sartorius CP64).

\section{Measuring individual size}

The extent of helper control over the investment ratio could depend on the outcome of aggressive/coercive interactions between queens and helpers (Heinze et al., 1994; Ratnieks et al., 2006; Smith et al., 2011). For example, queens that are large are likely to be able to physically dominate relatively smaller helpers, thereby reducing helper control. Queen and average helper absolute wing size difference $(\mathrm{mm})$ was therefore used as a covariate in analyses of investment ratios. The forewing was removed and placed between two microscope slides, before being photographed and measured $(\times 1.6$ magnification on Leica M165 C; see Online Resource 1 for exact position of wing measurement).

\section{Microsatellite genotyping and relatedness}

B2 brood and adult genotypes (including removed helpers) were determined using microsatellite genotyping (see Parsons et al., 2017 for methodology and further details). In 2017 and $2018,93 \% \pm 1.4$ and $94 \% \pm 0.9$ of the total brood for each nest was successfully genotyped. A mean of $2.4 \pm 0.2$ helpers $(77 \% \pm 8.0$ of the maximum number of helpers determined from videos) and $2.8 \pm 0.2$ helpers $(70 \% \pm 4.1$ of the maximum) were genotyped for each colony in 2017 and 2018. All samples were genotyped at 16 variable loci (Online Resource 2). Individual sex was assigned by observing the number of peaks present on GeneMapper 3.7 (Applied Biosystems). Where individuals showed a single peak across all loci (indicating homozygosity), they were assigned as male. Individuals with double peaks (indicating heterozygosity) were assigned as female. All female brood belonged to the queen, as B1 helpers did not have the opportunity to mate and lay female eggs. The queen genotype could be inferred from the genotypes of female brood, so that queen absence/presence was easily identified. Multiple paternity was identified among daughters by the presence of a different paternal allele at 2 or more loci. Helper-laid B2 offspring could be recognised when there were loci with alleles matching helper, but not queen, genotypes. Unrelated 'alien' B1 helpers were identified when there were two or more loci where neither B1 allele matched the queen genotype (see Online Resource 3 for nest compositions). We tested for linkage disequilibrium (LD) and departure from HardyWeinberg equilibrium (HW) within the 2017 and 2018 datasets using GENEPOP 4.2 (Raymond and Rousset, 1995; Rousset, 2008). To carry out these tests, we selected one female from each nest to avoid pseudoreplication. To correct for multiple testing, we used the BenjaminHochberg procedure to control the false discovery rate (Benjamini and Hochberg, 1995). As a measure of genetic diversity, we also recorded the number of alleles at each locus and the observed and expected heterozygosity (full results presented in Online Resource 4). After correction for multiple testing, no locus pairs were significant for LD. One locus deviated from HW in both 2017 and 2018 (LMA 51; Online Resource 4). Mean expected per-locus heterozygosity was $0.78 \pm 0.03$ and $0.77 \pm 0.03$ in 2017 and 2018 , respectively, confirming that the markers were powerful for inferring colony genetic structure. The probability of non-detection of a second fathering male was very low (2017: $P=8.16 \mathrm{e}^{-12}$; 2018: $P=1.47 \mathrm{e}^{-11}$; using $\mathrm{D}_{\mathrm{p}}$ equation from Soro et al., 2009), and the proportion of B2 males for which maternity was assignable was $>0.999$ (equation from Palmer et al., 2002).

Throughout this study, relatedness between helpers and different classes of brood were assumed as full sisters = 0.75 ; half sisters $=0.25$ (assumes fathering males were unrelated); brothers $=0.25$; nephews $=0.375$; nieces $=0.375$; half nephews $=0.125$; half nieces $=0.125$; unrelated $=0$. To examine whether these expected values were close to observed values, we used Relatedness 5.0.8 Software (Queller and Goodnight, 1989) to estimate the coefficient of relatedness $(r)$ among helpers on single paternity nests that were assumed to be full sisters, and between helpers and aliens that were assumed to be unrelated. Allele frequencies were estimated and calculations performed while weighting nests equally. Standard errors and $95 \%$ confidence intervals $(95 \%$ CI) were obtained by jackknifing over nests (Queller and Goodnight, 1989). As expected, full sisters showed $r$-values close to 0.75 (2017: within-nests mean $r=0.74$ [95\% CI $=0.59-0.89$ ]; 2018: within-nests mean $r=0.77$ [95\% CI $=0.57-0.97]$ ). Similarly, $r$-values between helpers and alien helpers were close to zero (2017: within-nests mean $r=0.10$ [95\% CI $=-$ 0.22-0.43]; 2018: within-nests mean $r=0.06$ [95\% CI $=-$ $0.28-0.45])$.

\section{Statistical analyses}

All statistical analyses were performed in R (version 3.6.1; $\mathrm{R}$ Core Team, 2019). With all generalised linear models (GLMs) used, we assessed the significance of fixed effects by using the 'drop1' function, which employs loglikelihood ratio tests to identify terms eligible to be removed from the model, followed by sequential removal of non-significant terms. 


\section{Colony-level investment ratios in queen-right versus orphaned colonies}

To test whether colony orphaning affected the B2 sex investment ratio, we used a quasibinomial GLM ('car' package: Fox et al., 2020) with proportional investment in female B2 as the response variable and presence of the queen $(\mathrm{Y} / \mathrm{N})$ and year as fixed effects.

\section{Other potential correlates of the investment ratio}

In queen-right colonies, multiple paternity and the presence of 'alien' helpers reduces average relatedness of helpers to female brood, thereby altering the optimum investment ratio per colony. For example, helpers are more closely related to full sisters $(r=0.75)$ than they are to half sisters $(r=0.25)$, and 'alien' helpers are unrelated to brood produced by the queen. We assessed how multiple paternity and the presence of aliens affected average helper-brood relatedness using a quasibinomial GLM, with average relatedness of helpers to female B2 as the response and number of fathers and proportion of alien helpers as fixed effects.

We then tested whether alien helpers and multiple paternity affected the investment ratio in queen-right colonies, using a quasibinomial GLM. Proportional investment in female B2 was the response variable and fixed effects were the proportion of alien helpers, number of fathers, group size, number of days of nest activity (excluding days where no foraging occurred due to inclement weather), queen-helper size difference and year. In a separate model, we replaced the proportion of alien helpers and number of fathers with the average relatedness of helpers to female B2. A potential issue with testing for an effect of helper-female B2 relatedness in this second analysis is the inclusion of the genotypes of helpers that we removed from nests. Removed helpers were present during only the first $\sim$ week of brood production. We therefore repeated the analysis but excluded both removed helpers and pupal brood, i.e. brood most likely to have been produced before helper removal. We tested for collinearity between fixed effects using the 'vif' function in R ('car' package: Fox et al., 2020). For all models, VIF scores were low $(<2.5)$, indicating no significant collinearity.

\section{Average relatedness of helpers to brood}

Using the full dataset, we calculated average relatedness of helpers to B2 for each colony and compared queen-right and orphaned colonies. For orphaned colonies, helpers that became egg-layers were included in this calculation. We used a quasibinomial model, with relatedness as the response variable and presence of the queen $(\mathrm{Y} / \mathrm{N})$ and year as fixed effects. Additionally, a Wilcoxon 1-sample signed ranks test was used ('wilcox.test' function in R) to test whether average helper-brood relatedness differed from 0.5 in each year. Relatedness estimates below or equal to 0.5 would suggest that relatedness benefits alone do not maintain sociality in L. malachurum.

\section{Results}

The frequency of orphanage in the population was high, with $29 \%$ (10 out of 35 ) and $32 \%$ (24 out of 74 ) of colonies having no queen at the time of nest excavation in 2017 and 2018 respectively. Some orphaned colonies contained both male and female B2 offspring laid by the original queen (2017: $70 \%, 7$ out of 10; 2018: 67\%, 16 out of 24), while other colonies contained exclusively male $\mathrm{B} 2$ produced by unmated helpers (2017: 30\%, 3 out of 10; 2018: 33\%, 8 out of 24).

Among queen-right colonies, the number of fathers ranged from 1 to $3($ mean $=1.23 \pm 0.1)$ to $1-4($ mean $=1.57 \pm 0.1)$ in 2017 and 2018, respectively, with $24 \%$ (6 out of 25 ) and $48 \%$ (24 out of 50) of queen-right colonies showing multiple paternity. Average effective mating frequency (Starr, 1984) across all queen-right colonies was $1.1 \pm 0.05$ in 2017 (range 1.2-2 in multiple paternity colonies) and $1.4 \pm 0.07$ in 2018 (range 1.23.1 in multiple paternity colonies). A mean of $23 \%$ and $28 \%$ of helpers were identified as 'alien' in queen-right colonies in 2017 and 2018, ranging between 0 and 100\% for individual colonies. Cases where two or more related aliens were identified were likely a result of nest usurpation (Paxton et al., $2002 b$ ) in the founding stage, after the original foundress had already provisioned multiple B1 offspring. Other colonies had single alien helpers, possibly resulting from the so-called drifting between nests (e.g. Pfeiffer and Crailsheim, 1998; Soro et al., 2009) during the helper foraging phase. Helperlaid male eggs were identified in 12\% (2017: 3 out of 25; 2018: 6 out of 50) of queen-right colonies across both years. In $56 \%$ of these cases, an alien helper had laid eggs, and in $22 \%$, the queen had mated multiply. The remaining cases consisted of a colony where the queen was infected with a large conopid parasite (identified during dissection) and another colony where the egg-laying helper was unusually large relative to the queen. In total, $3 \%$ of male B2 in queen-right colonies were helper-laid. Mean helper-female B2 relatedness for queen-right colonies was $0.54 \pm 0.06$ in 2017 and $0.47 \pm$ 0.04 in 2018 (see Online Resource 5 for relatedness estimates per colony).

\section{Colony-level investment ratios in queen-right versus orphaned colonies}

In queen-right colonies, the $\mathrm{B} 2$ investment ratio was femalebiased, with a ratio of 2.3:1 in favour of female brood in both 2017 and 2018 (Fig. 1). In contrast, orphaned colonies invested comparatively more in male brood, with an 
Fig. 1 Boxplots showing the distributions of proportional investment in female $\mathrm{B} 2$ relative to male $\mathrm{B} 2$ across colonies for each nest type in 2017 and 2018. Proportional investment in females of 0.5 represents a $1: 1$ investment ratio. Points represent individual colonies

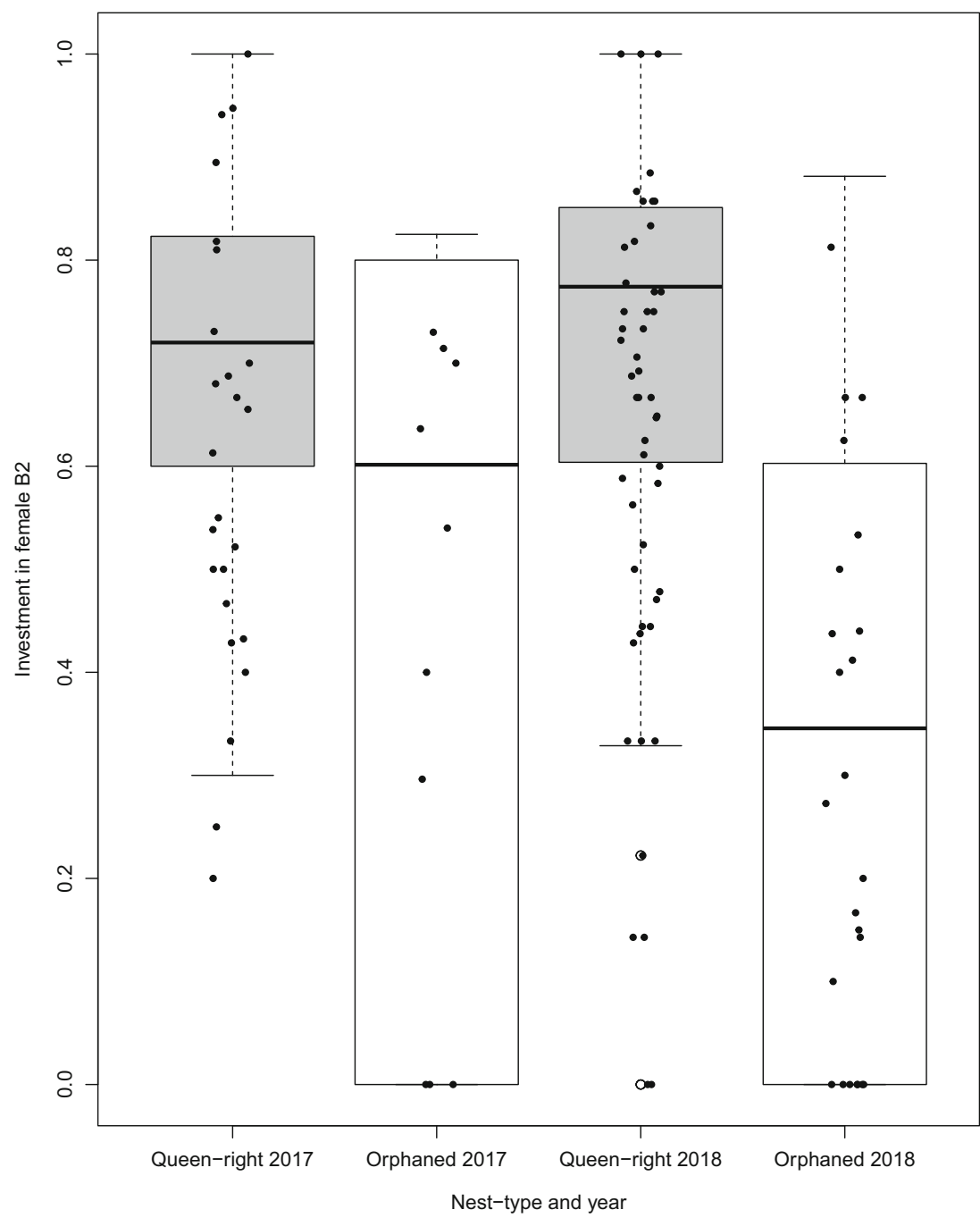

investment ratio of 1:1.1 in favour of male brood in 2017 and $1: 1.8$ in favour of male brood in 2018 (mean of 1:1.5; Fig. 1). There was thus a split sex ratio in the population, with queenright colonies investing significantly more in the production of female B2 than orphaned colonies $\left(\mathrm{X}^{2}{ }_{1}=39.7, P=<0.001\right)$. There was no significant effect of year on investment in female B2 $\left(\mathrm{X}^{2}{ }_{1}=0.90, P=0.342\right)$.

\section{Other potential correlates of the investment ratio}

In a subset of queen-right colonies where information on group size was available, both the number of fathers $\left(\mathrm{X}^{2}{ }_{1}=\right.$ $66.02, P=<0.001)$ and the proportion of alien helpers $\left(\mathrm{X}^{2}{ }_{1}=\right.$ $487.85, P=<0.001$ ) had independent, negative effects on the average relatedness of helpers to female B2. However, neither the number of fathers $\left(\mathrm{X}^{2}{ }_{1}=0.005, P=0.94\right)$ nor the proportion of alien helpers $\left(\mathrm{X}^{2}{ }_{1}=0.34, P=0.56\right)$ had a significant effect on the investment in female B2. Similarly, investment in female B2 did not vary with group size $\left(\mathrm{X}^{2}{ }_{1}=0.09, P=\right.$ $0.76)$, the relatedness of helpers to female $\mathrm{B} 2\left(\mathrm{X}^{2}{ }_{1}=21.2, P=\right.$
$0.17)$, the number of days of nest activity $\left(\mathrm{X}^{2}{ }_{1}=2.24, P=\right.$ $0.13)$, or year $\left(\mathrm{X}_{1}{ }_{1}=0.02, P=0.88\right)$. However, there was a significant negative correlation between queen-helper size difference and investment in female B2: a bigger size difference was correlated with less investment in female $\mathrm{B} 2\left(\mathrm{X}^{2}{ }_{1}=4.37\right.$, $P=0.03$; Fig. 2). The effect of helper-female B2 relatedness on investment in female B2 was qualitatively unchanged when removed helpers and pupal brood were excluded from the analysis (Online Resource 6).

\section{Average relatedness of helpers to brood}

Mean relatedness of helpers to B2 brood for queen-right colonies was $0.40 \pm 0.04$ and $0.35 \pm 0.03$ in $2017(n=25)$ and $2018(n=50)$ respectively. For orphaned colonies, mean relatedness of helpers (including the primary egg-layer) to B2 brood was $0.50 \pm 0.03$ and $0.41 \pm 0.03$ in $2017(n=10)$ and 2018 ( $n=24)$ respectively. There was a marginally significant trend for orphaned colonies to have higher helper-brood relatedness than queen-right colonies $\left(\mathrm{X}^{2}{ }_{1}=3.29, P=0.07\right)$, and 
Fig. 2 Scattergraph showing the relationship between queenhelper size difference $(\mathrm{mm})$ and proportional investment in female $\mathrm{B} 2$ relative to male $\mathrm{B} 2$.

Proportional investment in females of 0.5 represents a $1: 1$ investment ratio. Points represent individual colonies in 2017 (light) and 2018 (dark). Lines of best fit (predicted from the GLM) and standard errors for each year are represented by solid and broken lines respectively

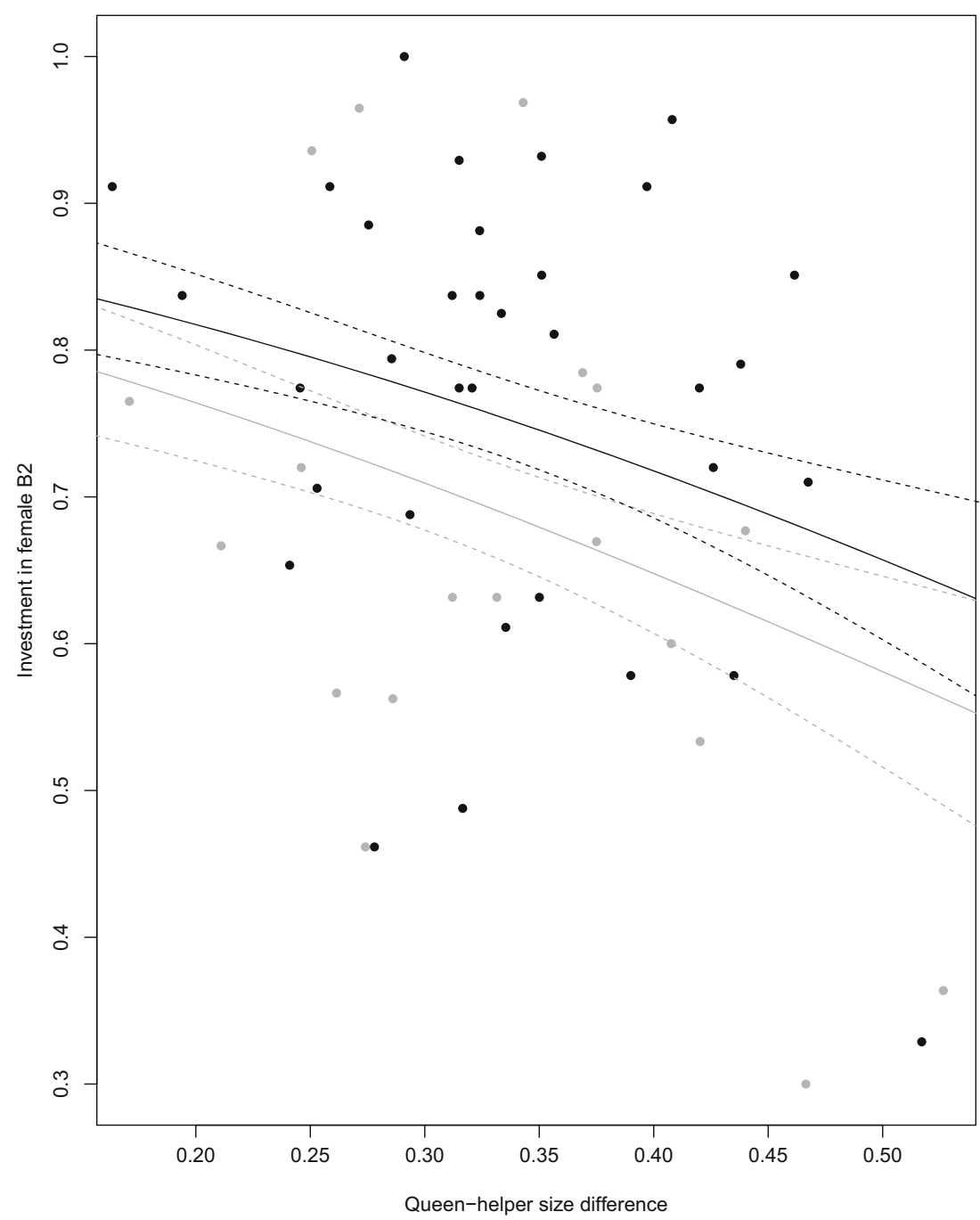

no significant effect of year $\left(\mathrm{X}^{2}{ }_{1}=2.70, P=0.10\right)$. The average relatedness of helpers to brood when averaged across all colonies was $0.43 \pm 0.03$ and $0.37 \pm 0.02$, for 2017 and 2018 respectively. Helper-brood relatedness did not differ significantly from 0.5 in 2017 ( $\mathrm{V}=192.5, P=0.12)$. However, helper-brood relatedness was significantly lower than 0.5 in 2018 (V=450, $P=<0.001)$.

A difference between the two years of our study was that a greater percentage of nests were still open in $2018(69 \%)$ at the time of excavation, than in 2017 (40\%). If B2 production is protandrous, it is possible that proportionally more females would have been produced in 2018 if nests had been left for longer prior to excavation, so that average helper-brood relatedness might be artificially low. Protandry is widespread in bees and has been demonstrated in a Greek population of L. malachurum, albeit based on a small number of colonies (Wyman and Richards, 2003: $n=7$; Richards et al., 2005: $n=$ 10). However, as stated above, we found no correlation between the number of days a nest was active for and the proportional investment in female brood. Additionally, the proportion of female brood was not significantly correlated with brood developmental stage in either year (Online Resource 6).

\section{Discussion}

Halictid bees such as L. malachurum are primitively eusocial, with recent origins of eusociality (Brady et al., 2006). They are characterised by small group sizes, low levels of queenhelper dimorphism and reproductive totipotency in helpers. We found that a surprisingly large proportion (approximately one third) of L. malachurum colonies were orphaned before the end of the nesting cycle. Colonies produced more femalebiased B2 sex investment ratios when the original queen was present than when a helper had replaced her. This difference in sex investment based on queen status was at least partly due to unmatedness constraining helpers to male-only brood production. This in turn should drive bees in queen-right colonies to produce a more female-biased ratio. In queen-right colonies, 
helpers did not seem to adjust B2 investment ratios in response to other factors that reduced average helper-brood relatedness (multiple paternity and the presence of unrelated 'alien' helpers). However, colonies where the queen was relatively large compared with her helpers produced a less female-biased B2 brood. Average helper-brood relatedness was less than 0.5 in both years, significantly so in 2018 . Below we discuss these results in more detail.

\section{Sex investment ratios in queen-right versus orphaned colonies}

We found clear evidence of a split sex ratio, with orphaned colonies investing more in males (average investment ratio of 1:1.5 in favour of male brood across both years) and queenright colonies investing more in females (average investment ratio of 2.3:1 in favour of female brood across both years). Trivers and Hare (1976) showed that if helpers in queen-right colonies are to capitalise on the relatedness asymmetries arising from haplodiploidy, they should bias brood investment in favour of females. For orphaned colonies with replacement queens, it is advantageous to specialise on male production (Mueller, 1991): helpers are equally related to nephews and nieces $(r=0.375)$, and the reproductive value of males will be high due to the overproduction of females in queen-right colonies. In our study, however, orphaned colonies were constrained to male-only brood production after queen death, since replacement queens were unable to mate in the absence of males in the helper phase. This overproduction of males in orphaned colonies means that helpers in queen-right colonies can gain inclusive fitness benefits by strategically rearing a more female-biased sex ratio, without the reproductive value of females decreasing (Grafen, 1986; Seger, 1983).

\section{Queen versus helper control of the sex investment ratio}

Female-biased investment ratios of the kind we documented in both years of our study are common in queen-right colonies of eusocial Hymenoptera, and have been suggested to signify helper control over the investment ratio (Bourke and Franks, 1995; Chapuisat and Keller, 1999; Trivers and Hare, 1976; Mehdiabadi et al., 2003). Helpers are expected to favour a 3:1 investment ratio in favour of females in queen-right colonies (Trivers \& Hare, 1976), whereas queens favour a 1:1 investment ratio. We now discuss mechanisms that could influence the effectiveness of helper control in our population of L. malachurum.

\section{Group size effects}

Frank and Crespi (1989) proposed a verbal model in which a larger number of helpers causes excess provisions per offspring within a colony, indirectly favouring production of the sex that is normally larger (females). An experimental increase in the amount of pollen per brood has indeed been shown to increase female bias in halictids (Plateaux-Quenu, 1988). It seems feasible that Frank and Crespi's model could apply to sweat bees, because eggs are typically laid at the end of the day (Batra, 1968), so that provisions per offspring might depend on the amount of pollen brought back by helpers during that day. Consistent with this idea, a study on Halictus ligatus found a positive correlation between group size and the weight of pollen masses (Boomsma and Eickwort, 1993). However, we found no evidence that group size affects the proportion of females produced by queen-right colonies of L. malachurum. It is possible that a group size effect could occur in southern European populations, where more than one helper-brood results in larger group sizes (Paxton et al., 2002b; Strohm and Bordon-Hauser, 2003; Soro et al., 2009).

\section{Direct manipulation by helpers}

It may be that helpers are able to manipulate the size of pollen masses more directly through mechanisms that are unrelated to the size of the group. Although it is helpers that return to the nest with pollen, it is unclear whether they or the queen are involved in creating the pollen mass onto which the egg is laid. Direct involvement from helpers would provide a context through which they could influence the queen's sex ratio decisions. Fratricide, which involves the elimination of male eggs from the nest (e.g. in ants: Chapuisat et al., 1997), could also enable helpers to modify the sex ratio. Oophagy is a potential method of fratricide that has been documented in both queen and helper sweat bees (Halictus poeyi: Packer, 1987; Lasioglossum versatum: Batra, 1968). In L. malachurum, brood cells are periodically opened after eggs are laid by the queen (Knerer and Plateaux-Quenu, 1966), enabling helpers to access the brood. However, we do not know whether helpers are able to discern the sex of the egg laid in L. malachurum, or to what extent queen or helper policing would prevent fratricide.

\section{Informational constraints}

If helpers in queen-right colonies are able to fully control the sex ratio of reproductives, we would expect to see colonylevel sex investment changes in response to differences in queen mating frequency and the presence of alien helpers (Boomsma, 1991); however, we did not see such effects. There was considerable variation in the number of males fathering the B2 brood, but this was not correlated with investment ratios. Similarly the presence of alien helpers that were unrelated to both the queen and the brood ( $26 \%$ of helpers) was not associated with more male-biased sex investment ratios. In fact, there was no overall effect of average relatedness 
between helpers and female brood on investment ratios in queen-right nests. This superficially contrasts with previous research by Packer and Owen (1994), who found a positive correlation between relatedness asymmetry and investment in female brood in the sweat bee Lasioglossum laevissium. Their result suggests that helpers can respond to colony genetic structure to some extent. However, it is possible that helpers are able to respond to relatedness asymmetries correlated with obvious environmental cues such as the death of the queen, but not those caused by multiple paternity or aliens. Cuticular hydrocarbon cues (Ayasse et al., 1990; Smith and Wenzel, 1988) would be one means of identifying individuals based on levels of relatedness, but sharing resources within a nest could affect the reliability of such cues (Sorvari et al., 2008; van Zweden et al., 2010; reviewed in van Zweden and d'Ettorre, 2010). An analysis by Soro et al. (2011) identified a genetic component to odour bouquets in L. malachurum, but suggested that there is not enough information in these cues to differentiate between nest mates with varying levels of relatedness. In their study, even alien helpers were chemically indistinguishable from other helpers.

\section{Queen control}

Helpers might be expected to counteract reduced relatedness to the queen's offspring by laying their own male eggs. However, we found that helpers produced male offspring in only $12 \%$ of queen-right colonies (3\% of males overall were helper-produced). Variation between L. malachurum populations in the degree of helper oviposition is thought to result from differences in the effectiveness of queen control brought about by geographical variation in group sizes (Paxton et al., 2002b; Richards et al., 2005), although this remains untested. While previous research has revealed that some L. malachurum helpers have developed ovaries (Packer \& Owen, 1994; Richards, 2000; Wyman \& Richards, 2003; Strohm and Bordon-Hauser, 2003; Richards et al., 2005), there is little direct evidence of helper oviposition. One possible explanation is that queens exert significant control over reproduction and sex investment: the relatively small colony sizes in our population make this feasible. Consistent with this idea, we found that in both years, colonies with greater queenhelper size dimorphism invested less in the production of females. Larger queens may be able to control helper behaviour more effectively, for example through aggression and/or elimination of helper-laid offspring (Smith and Weller, 1989; Pabalan et al., 2000; Smith et al., 2019; but see Soro et al., 2009). It is also plausible that larger queens can more effectively prevent helper oophagy of male brood, and that they are better able to direct helpers to form smaller pollen masses, favouring male brood production. As L. malachurum nests are situated below ground level, we were unable to observe queen-helper interactions in our field study. However, queens have been shown to influence helper task management within laboratory nests of other sweat bee species (Breed and Gamboa, 1977; Dalmazzo and Roig-Alsina, 2018), although the effect of queen size is unknown.

\section{Average relatedness of helpers to brood}

We found that average relatedness of helpers to the brood that they rear is 0.37 in queen-right colonies and 0.44 in orphaned colonies. Helper-brood relatedness was not significantly different from 0.5 in 2017 , but was significantly lower than 0.5 in 2018. Other studies of diverse primitively eusocial insects also suggest values below 0.5 , which show that helpers are generally less related to the brood than they would be if they reproduced solitarily (Gadagkar et al., 1991; Sumner et al., 2007; Field, 2008; Brand and Chapuisat, 2016; Gadagkar, 2016). Helper-brood relatedness values equal to or below 0.5 suggest that ecological benefits of helping (Field, 2008), or perhaps coercion, must help to maintain eusociality, since helpers could instead produce their own offspring $(r=0.5)$ by nesting independently.

Interestingly, we found a marginally significant trend for helpers to be more closely related to B2 brood in orphaned colonies than queen-right colonies. A contributor to this is that alien helpers, which are common in our study population, reduce average helper-brood relatedness in queen-right colonies where there is little reproduction by helpers. In orphaned colonies, however, aliens may reproduce themselves as replacement queens, or reproduce indirectly when multiple aliens in the same colonies are sisters, thereby raising average helper-brood relatedness.

\section{Conclusions}

We have identified a split sex ratio in a southern UK population of L. malachurum caused by colony orphanage, which because of unmatedness in replacement queens leads to maleonly offspring production. We found a female-biased investment ratio in queen-right colonies, suggesting at least partial helper control over the sex ratio. The extent of female bias was not correlated with group size or helper-brood relatedness, despite variation in relatedness caused by alien helpers and variation in the number of fathers. Queens may have some degree of control over the investment ratio, since colonies with greater caste size dimorphism invested less in the production of females. Helper-brood relatedness estimates $\leq 0.5$ indicate that relatedness benefits alone are not enough to maintain eusociality in our study population.

Supplementary Information The online version contains supplementary material available at https://doi.org/10.1007/s00265-020-02944-8. 
Acknowledgments We would like to thank Thomas Price, Paul Davison, Brinna Barlow, Georgie Hall, Lucy Neame and Antoine Melet for valuable assistance in the field. Many thanks also to Lizzy Salkus, Bethany Pihama, Samantha Salt, Emily Gilford, Lewis Flintham, Ellie Sandison and Freya Neve-O'Dwyer for assisting with video data collection and to three anonymous reviewers who helped to improve the manuscript. We are also grateful to Charles Burrell, Penny Green and the team at Knepp Estate for their support and permission to conduct research on the site. This work is part of a project that has received funding from the European Research Council (ERC) under the European Horizon's 2020 research and innovation programme (grant agreement No.695744). It was also supported by the Natural Environment Research Council (grant number NE/M003191/1 to JF) including NERC Biomolecular Analysis Facility (NBAF) grant 923 to JF.

Code availability Code will be made available on request.

Authors' contributions Project conceptualisation and design: TMP and JF. Data collection and analysis: TMP.

Funding Funded by the European Research Council (ERC) and Natural Environment Research Council (NERC).

Data availability Data are available on the Open Science Framework https://doi.org/10.17605/OSF.IO/7RBMX.

\section{Compliance with ethical standards}

Conflict of interest The authors declare that they have no conflicts of interests.

Ethics approval Not applicable.

Consent to participate Not applicable.

Consent for publication Not applicable.

Open Access This article is licensed under a Creative Commons Attribution 4.0 International License, which permits use, sharing, adaptation, distribution and reproduction in any medium or format, as long as you give appropriate credit to the original author(s) and the source, provide a link to the Creative Commons licence, and indicate if changes were made. The images or other third party material in this article are included in the article's Creative Commons licence, unless indicated otherwise in a credit line to the material. If material is not included in the article's Creative Commons licence and your intended use is not permitted by statutory regulation or exceeds the permitted use, you will need to obtain permission directly from the copyright holder. To view a copy of this licence, visit http://creativecommons.org/licenses/by/4.0/.

\section{References}

Alexander RD (1974) The evolution of social behavior. Annu Rev Ecol Syst 5:325-383

Ayasse M, Engels W, Hefetz A, Lübke G, Francke W (1990) Ontogenetic patterns in amounts and proportions of Dufour's gland volatile secretions in virgin and nesting queens of Lasioglossum malachurum (Hymenoptera: Halictidae). Z. Für Naturforschung C 45:709-714. https://doi.org/10.1515/znc-1990-0623
Batra SWT (1968) Behavior of some social and solitary halictine bees within their nests: a comparative study (Hymenoptera: Halictidae). J Kans Entomol Soc 41:120-133

Benjamini Y, Hochberg Y (1995) Controlling the false discovery rate: a practical and powerful approach to multiple testing. J R Stat Soc Ser B Methodol 57:289-300. https://doi.org/10.1111/j.2517-6161. 1995.tb02031.x

Boomsma JJ (1991) Adaptive colony sex ratios in primitively eusocial bees. Trends Ecol Evol 6:92-95. https://doi.org/10.1016/ 01695347(91)90182-W

Boomsma JJ, Eickwort GC (1993) Colony structure, provisioning and sex allocation in the sweat bee Halictus ligatus (Hymenoptera: Halictidae). Biol J Linn Soc 48:355-377. https://doi.org/10.1016/ 0024-4066(93)90006-A

Bourke AFG (1994) Worker matricide in social bees and wasps. J Theor Biol 167:283-292. https://doi.org/10.1006/jtbi.1994.1070

Bourke AFG, Franks NR (1995) Social evolution in ants. Princeton UniversityPress

Brady SG, Sipes S, Pearson A, Danforth BN (2006) Recent and simultaneous origins of eusociality in halictid bees. Proc Royal Soc B 273: $1643-1649$

Brand N, Chapuisat M (2016) Low relatedness and frequent inter-nest movements in a eusocial sweat bee. Insect Soc 63:249-256. https:// doi.org/10.1007/s00040-015-0460-0

Breed MD, Gamboa GJ (1977) Behavioral control of workers by queens in primitively eusocial bees. Science 195:694-696

Bull NJ, Schwarz MP (2001) Brood insurance via protogyny: a source of female-biased sex allocation. Proc R Soc Lond B Biol Sci 268: 1869-1874. https://doi.org/10.1098/rspb.2001.1687

Chapuisat M, Keller L (1999) Testing kin selection with sex allocation data in eusocial Hymenoptera. Heredity 82:473-478. https://doi.org/ 10.1038/sj.hdy. 6885340

Chapuisat M, Liselotte S, Keller L (1997) Sex-ratio regulation: the economics of fratricide in ants. Proc R Soc Lond B Biol Sci 264:12551260. https://doi.org/10.1098/rspb.1997.0173

Cole BJ (1983) Multiple mating and the evolution of social behavior in the Hymenoptera. Behav Ecol Sociobiol 12:191-201. https://doi. org/10.1007/BF00290771

Crozier RH, Smith BH, Crozier YC (1987) Relatedness and population structure of the primitively eusocial bee Lasioglossum zephyrum (Hymenoptera: Halictidae) in Kansas. Evolution 41:902-910. https://doi.org/10.1111/j.1558-5646.1987.tb05863.x

Couchoux C, Field J (2019) Parental manipulation of offspring size in social groups: a test using paper wasps. Behav Ecol Sociobiol 73:36. https://doi.org/10.1007/s00265-019-2646-3

Dalmazzo M, Roig-Alsina A (2018) Dominant-subordinate social interactions and subordinate behavioral responses in the primitively eusocial sweat bee Augochlora phoemonoe (Hymenoptera: Halictidae). Apidologie 49:852-861

Dunn T, Richards MH (2003) When to bee social: interactions among environmental constraints, incentives, guarding, and relatedness in a facultatively social carpenter bee. Behav Ecol 14:417-424. https:// doi.org/10.1093/beheco/14.3.417

Field J (2008) The ecology and evolution of helping in hover wasps (Hymenoptera: Stenogastrinae). In: Korb J, Heinze J (eds) Ecology of social evolution. Springer, Berlin

Field J, Shreeves G, Sumner S, Casiraghi M (2000) Insurance-based advantage to helpers in a tropical hover wasp. Nature 404:869 871. https://doi.org/10.1038/35009097

Fjerdingstad EJ, Gertsch PJ, Keller L (2002) Why do some social insect queens mate with several males? testing the sex-ratio manipulation hypothesis in Lasius niger. Evolution 56:553-562

Foitzik S, Kureck IM, Rüger MH, Metzler D (2010) Alternative reproductive tactics and the impact of local competition on sex ratios in the ant Hypoponera opacior. Behav Ecol Sociobiol 64:1641-1654 
Fox J, Weisberg S, Price B, Adler D et al (2020) Package 'Car.' Available online at: https://cran.r-project.org/web/packages/car/car. pdf

Frank SA, Crespi BJ (1989) Synergism between sib-rearing and sex ratio in Hymenoptera. Behav Ecol Sociobiol 24:155-162. https://doi.org/ 10.1007/BF00292098

Gadagkar R (2016) Evolution of social behaviour in the primitively eusocial wasp Ropalidia marginata: do we need to look beyond kin selection? Philos. Trans R Soc B Biol Sci 371:20150094. https://doi. org/10.1098/rstb.2015.0094

Gadagkar R, Chandrashekara K, Chandran S, Bhagavan S (1991) Worker-brood genetic relatedness in a primitively eusocial wasp. Naturwissenschaften. 78:523-526

Gadagkar R, Hamilton WD, Bone Q (1990) Evolution of eusociality: the advantage of assured fitness returns. Philos Trans R Soc Lond Ser B Biol Sci 329:17-25. https://doi.org/10.1098/rstb.1990.0146

Grafen A (1986) Split sex ratios and the evolutionary origins of eusociality. J Theor Biol 122:95-121. https://doi.org/10.1016/S00225193(86)80227-2

Heinze J, Holldobler B, Peeters C (1994) Conflict and cooperation in ant societies. Naturwissenschaften 81:489-497. https://doi.org/10.1007/ s001140050114

Hogendoorn K, Zammit J (2001) Benefits of cooperative breeding through increased colony survival in an allodapine bee. Insect Soc 48:392-397. https://doi.org/10.1007/PL00001796

Knerer G (1992) The biology and social behaviour of Evylaeus malachurus (K.) (Hymenoptera; Halictidae) in different climatic conditions of Europe. Zoologishes Jahrbuch für Systematik 119: 261-290

Knerer G, Plateaux-Quenu C (1966) Sur limportance de louverture des cellules a couvain dans levolution des Halictinae (insectes Hymenopteres) sociaux. Comptes rendus hebdomadaires des seances de 1 academie des sciences serie d 263:1622

Kukuk PF (1989) Evolutionary genetics of a primitively eusocial halictine bee, Dialictus zephyrus. In: Page RE. Breed MD (eds) The genetics of social evolution. Westview, Colorado

Leadbeater E, Carruthers JM, Green JP, Rosser NS, Field J (2011) Nest inheritance is the missing source of direct fitness in a primitively eusocial insect. Science 333:874-876. https://doi.org/10.1126/ science. 1205140

Lopez-Vaamonde C, Koning JW, Brown RM, Jordan WC, Bourke AFG (2004) Social parasitism by male-producing reproductive workers in a eusocial insect. Nature 430:557-560

Mehdiabadi NJ, Reeve HK, Mueller UG (2003) Queens versus workers: sex-ratio conflict in eusocial Hymenoptera. Trends Ecol Evol 18: 88-93. https://doi.org/10.1016/S0169-5347(02)00056-3

Meunier J, West SA, Chapuisat M (2008) Split sex ratios in the social Hymenoptera: a meta-analysis. Behav Ecol 19:382-390. https://doi. org/10.1093/beheco/arm143

Mueller UG (1991) Haplodiploidy and the evolution of facultative sex ratios in a primitively eusocial bee. Science $254: 442-444$. https:// doi.org/10.1126/science.254.5030.442

Pabalan N, Davey K, Packer L (2000) Escalation of aggressive interactions during staged encounters in Halictus ligatus say (Hymenoptera: Halictidae), with a comparison of circle tube behaviors with other halictine species. J Insect Behav 13:627-650

Packer, L. 1987. Competition over oviposition in subtropical and temperate populations of the social sweat bee Halictus ligatus. In: Eder J, Rembold H (eds) Chemistry and biology of social insects, Verlag J. Peperny, Munchen

Packer L, Knerer G (1985) Social evolution and its correlates in bees of the subgenus Evylaeus (Hymenoptera; Halictidae). Behav Ecol Sociobiol 17:143-149. https://doi.org/10.1007/BF00299246

Packer L, Owen RE (1994) Relatedness and sex ratio in a primitively eusocial halictine bee. Behav Ecol Sociobiol 34:1-10. https://doi. org/10.1007/BF00175452
Palmer KA, Oldroyd BP, Quezada-Euán JJG, Paxton RJ, May-Itza WDJ (2002) Paternity frequency and maternity of males in some stingless bee species. Molec. Ecol. 11:2107-2113

Pamilo P (1991) Evolution of colony characteristics in social insects. I Sex allocation Am Nat 137:83-107

Parsons PJ, Couchoux C, Horsburgh GJ, Dawson DA, Field J (2017) Identification of 24 new microsatellite loci in the sweat bee Lasioglossum malachurum (Hymenoptera: Halictidae). BMC Res Notes 10:753. https://doi.org/10.1186/s13104-017-3089-4

Paxton RJ, Thorén PA, Estoup A, Tengö J (2002a) Queen-worker conflict over male production and the sex ratio in a facultatively polyandrous bumblebee, Bombus hypnorum: the consequences of nest usurpation. Molec Ecol 10:2489-2498

Paxton RJ, Ayasse M, Field J, Soro A (2002b) Complex sociogenetic organization and reproductive skew in a primitively eusocial sweat bee, Lasioglossum malachurum, as revealed by microsatellites. Mol Ecol 11:2405-2416. https://doi.org/10.1046/j.1365-294X.2002. 01620.x

Pfeiffer KJ, Crailsheim K (1998) Drifting of honeybees. Insect Soc 45: 151-167. https://doi.org/10.1007/s000400050076

Plateaux-Quenu C (1988) Réalisation expérimentale de grands individus de première couvée chez Evylaeus calceatus (Scop.) (Hym., Halictinae): biométrie et caste. Réalis. Expérimentale Gd. Individ. Prem. Couvée Chez Evylaeus Calceatus Scop Hym Halictinae Biométrie Caste 9:263-270

Queller DC (1994) Extended parental care and the origin of eusociality. Proc R Soc Lond B Biol Sci 256:105-111. https://doi.org/10.1098/ rspb.1994.0056

Queller DC, Goodnight KF (1989) Estimating relatedness using genetic markers. Evolution 43:258-275. https://doi.org/10.1111/j.15585646.1989.tb04226.x

R Core Team (2019) R: a language and environment for statistical computing. R Foundation for Statistical Computing, Vienna. http:// www.R-proje ct.org/

Ratnieks FLW, Boomsma JJ (1996) Paternity in eusocial Hymenoptera. Philos Trans R Soc Lond Ser B Biol Sci 351:947-975. https://doi. org/10.1098/rstb.1996.0087

Ratnieks FLW, Foster KR, Wenseleers T (2006) Conflict resolution in insect societies. Annu Rev Entomol 51:581-608. https://doi.org/10. 1146/annurev.ento.51.110104.151003

Ratnieks FLW, Reeve HK (1992) Conflict in single-queen hymenopteran societies: the structure of conflict and processes that reduce conflict in advanced eusocial species. J Theor Biol 158:33-65. https://doi. org/10.1016/S0022-5193(05)80647-2

Raymond M, Rousset F (1995) GENEPOP (version 1.2): population genetics software for exact tests and ecumenicism. J Hered 86: 248-249. https://doi.org/10.1093/oxfordjournals.jhered.a111573

Richards MH, French D, Paxton RJ (2005) It's good to be queen: classically eusocial colony structure and low worker fitness in an obligately social sweat bee. Mol Ecol 14:4123-4133. https://doi.org/10. 1111/j.1365-294X.2005.02724.x

Richards MH, Packer L, Seger J (1995) Unexpected patterns of parentage and relatedness in a primitively eusocial bee. Nature 373:239-241

Ross KG, Matthews RW (1989a) Population genetic structure and social evolution in the sphecid wasp Microstigmus comes. Am Nat 134: 574-598. https://doi.org/10.1086/284998

Ross KG, Matthews RW (1989b) New evidence for eusociality in the sphecid wasp Microstigmus comes. Anim Behav 38:613-619. https://doi.org/10.1016/S0003-3472(89)80006-5

Rousset F (2008) Genepop'007: a complete re-implementation of the genepop software for Windows and Linux. Mol Ecol Resour 8: 103-106. https://doi.org/10.1111/j.1471-8286.2007.01931.x

Schwarz MP, Richards MH, Danforth BN (2007) Changing paradigms in insect social evolution: insights from halictine and allodapine bees. Annu Rev Entomol 52:127-150. https://doi.org/10.1146/annurev. ento.51.110104.150950 
Seger J (1983) Partial bivoltinism may cause alternating sex-ratio biases that favour eusociality. Nature 301:59-62. https://doi.org/10.1038/ 301059a0

Smith AA, Hölldobler B, Liebig J (2011) Reclaiming the crown: queen to worker conflict over reproduction in Aphaenogaster cockerelli. Naturwissenschaften 98:237-240. https://doi.org/10.1007/s00114011-0761-8

Smith AR, Simons M, Bazarko V, Harach J, Seid MA (2019) Queenworker aggression in the facultatively eusocial bee Megalopta genalis. Insect Soc 66:479-490

Smith BH, Weller C (1989) Social competition among gynes in halictine bees: the influence of bee size and pheromones on behavior. J Insect Behav 2:397-411

Smith BH, Wenzel JW (1988) Pheromonal covariation and kinship in social bee Lasioglossum zephyrum (Hymenoptera: Halictidae). J Chem Ecol 14:87-94. https://doi.org/10.1007/BF01022533

Soro A, Ayasse M, Zobel MU, Paxton RJ (2011) Kin discriminators in the eusocial sweat bee Lasioglossum malachurum: the reliability of cuticular and Dufour's gland odours. Behav Ecol Sociobiol 65:641653. https://doi.org/10.1007/s00265-010-1066-1

Soro A, Ayasse M, Zobel MU, Paxton RJ (2009) Complex sociogenetic organization and the origin of unrelated workers in a eusocial sweat bee, Lasioglossum malachurum. Insect Soc 56:55-63. https://doi. org/10.1007/s00040-008-1037-y

Sorvari J, Theodora P, Turillazzi S, Hakkarainen H, Sundström L (2008) Food resources, chemical signaling, and nest mate recognition in the ant Formica aquilonia. Behav Ecol 19:441-447. https://doi.org/10. 1093/beheco/arm160

Starr CK (1984) Sperm competition, kinship and sociality in the aculeate Hymenoptera. In: Sperm competition and the evolution of animal mating systems (Smith RL, ed). London: Academic Press. 427-464

Strohm E, Bordon-Hauser A (2003) Advantages and disadvantages of large colony size in a halictid bee: the queen's perspective. Behav Ecol 14:546-553. https://doi.org/10.1093/beheco/arg039
Sumner S, Lucas E, Barker J, Isaac N (2007) Radio-tagging technology reveals extreme nest-drifting behavior in a eusocial insect. Curr Biol 17:140-145. https://doi.org/10.1016/j.cub.2006.11.064

Sundström L (1994) Sex-ratio bias, relatedness asymmetry and queen mating frequency in ants. Nature 367:266-267

Sundström L, Chapuisat M, Keller L (1996) Conditional manipulation of sex ratios by ant workers: a test of kin selection theory. Science 274: 993-995

Trivers RL, Hare H (1976) Haploidploidy and the evolution of the social insect. Science 191:249-263. https://doi.org/10.1126/science. 1108197

West SA (2009) Sex allocation. Princeton University Press

Wilson EO (1971) The insect societies. Harvard University Press, Cambridge, MA

Wyman LM, Richards MH (2003) Colony social organization of Lasioglossum malachurum Kirby (Hymenoptera, Halictidae) in southern Greece. Insect Soc 50:201-211

Yagi N, Hasegawa E (2012) A halictid bee with sympatric solitary and eusocial nests offers evidence for Hamilton's rule. Nat Commun 3: 939. https://doi.org/10.1038/ncomms 1939

Yanega D (1989) Caste determination and differential diapause within the first brood of Halictus rubicundus in New York (Hymenoptera: Halictidae). Behav Ecol Sociobiol 24:97-107. https://doi.org/10. 1007/BF00299641

van Zweden JS, Brask JB, Christensen JH, Boomsma JJ, Linksvayer TA, d'Ettore P (2010) Blending of heritable recognition cues among ant nestmates creates distinct colony gestalt odours but prevents withincolony nepotism. J Evol Biol 23:1498-1508

van Zweden JS, d'Ettorre P (2010) Nestmate recognition in social insects and the role of hydrocarbons. Insect hydrocarbons: biology, biochemistry and chemical ecology 11:222-243

Publisher's note Springer Nature remains neutral with regard to jurisdictional claims in published maps and institutional affiliations. 